\title{
A Simplified Method for Estimating Outflow from the Bottom of Snowpack
}

\author{
Masaya SHISHIDO \\ Meteorological Disaster Prevention Group, Disaster Prevention Technology Division \\ Yasushi KURIHARA \\ Meteorological Disaster Prevention Group, Disaster Prevention Technology Division (Former) \\ Daisuke TAKAHASHI \\ Yasushi KAMATA \\ Shigehiro IIKURA \\ Meteorological Disaster Prevention Group, Disaster Prevention Technology Division \\ To ensure the safety of train operations, it is important to estimate the outflow from the \\ bottom of snowpack which might incur a full-depth avalanche. Therefore, the authors exam- \\ ined a simplified method for estimating the outflow from the bottom of snowpack, which can \\ be applied to railway disaster prevention, on the basis of heat balance observations, snowmelt \\ observations and previous studies. Consequently, the simplified method, which combines a \\ snowmelt (heat balance) model and a percolation model, yields a good estimate of the outflow \\ from the bottom of snowpack at 1 hour intervals using four input data available from the \\ nearest AMeDAS: i.e., air temperature, precipitation, wind speed and duration of sunshine.
}

Keywords: outflow from snowpack, full-depth avalanche, snowmelt, heat balance method

\section{Introduction}

In snow-covered areas, at the beginning of spring, a large amount of snow melts on the snow surface and the water infiltrates the accumulated snow. In recent years, even in winter, temporary temperature rises have been observed and large volumes of rain and snowmelt have been recorded [1]. For example, in Sapporo on January 23, 2009 , the temperature rose to $7.6{ }^{\circ} \mathrm{C}$ in winter, and 18.5 $\mathrm{mm}$ of precipitation was observed. In such situations, it is known from a qualitative point of view, that water between snow and soil reduces the bearing capacity of the snowpack intensity of the snow, creating the danger of a full-depth avalanche increase. However, it is still unknown the extent to which rain or snowmelt affects the danger of a full-depth avalanche. Therefore, in railway companies, when the increase of the temperature or rain was observed in winter, rounds and watches are carried out based on empirical rules. In recent years, the number of employees with abundant experience however, is decreasing. In order to carry out suitable rounds and watches, it is important to clarify the relationship between snow-melt and full depth avalanche occurrence, which should then be taken into account in setting guidelines for rounds and watches in winter.

Consequently, progress has been made in research into a method for evaluating full-depth avalanche hazards. The methods being studied pay particular attention to estimating the outflow from the bottom of the snowpack, the relationship between outflows and bearing capacity of the snowpack, and analysis of the moving speed of the snowpack (glide speed). This report introduces a method for estimating outflow from the bottom of the snowpack.

\section{Estimation of the outflow from the bottom of the snowpack}

To estimate the outflow from the bottom of the snow pack, a method can be used to estimate the outflow directly (water equivalent method [2], lysimeter method [2]) or indirectly (degree-day method [1, 2]). The water equivalent method calculates outflow from the weight of the snowpack using snow pillows. The lysimeter method observes percolation through the snow pack and is set on the ground surface. Both methods have the advantage of offering direct observation of the outflow, but they also need large spaces $\left(10 \mathrm{~m}^{2}\right)$ to set the observation equipment and careful maintenance management to continue exact measurement. Therefore, it is not reasonable to install this observation equipment along tracks from the view point of cost and maintenance. On the other hand, the degree-day method calculates the outflow in relation to temperature simply using empirical rules based on the relationship between outflow and temperature. Because this method is easy, and is the same time cost efficient compared with other methods, it was further investigated with a view to application as a trackside disaster prevention measure.

For example, we use this method to predict avalanche along railroad, and when the avalanche is predicted we will make official announcement to the station etc.

The precision of the degree-day method is a daily moving average. As such it was difficult to compute outflow to reach a 1 hour time resolution required for railroad disaster prevention. The present research aimed to satisfy this requirement by examining techniques to estimate outflow per hour. In order for this method to be applied to railway disaster prevention it is preferable that input data be easily obtained. It was therefore determined that input values for this estimation method should be the observed data collected from the nearest AMeDAS (Automated Meteorological Data Acquisition System). Figure.1 shows the 
process for estimating outflow from the snowpack. It is necessary to estimate the outflow accurately every hour. Two phenomena found in snowpack, i.e. "snowmelt at snow-surface" and "infiltration in snowpack" where therefore considered separately. A model was then designed to estimate each phenomenon, based on weather/snowmelt observations and past research results. The following sections describe how each model was created and present the estimations subsequently obtained.

\section{Observation}

Snowmelt and weather data from the Shiozawa Snow Testing Station (Minami-Uonuma-shi, Niigata-ken,Japan) during the winter of 2011 were observed to obtain the data needed to develop a method for estimating outflow from the bottom of the snowpack. Observations were made of temperature, humidity, precipitation, snow depth, wind direction, wind speed, air pressure and solar radiation (hours of sunshine) (see Section 4.1). Outflow was measured with a lysimeter. Measurements were collected every ten minutes for 110 days from January 6 to April 25 (date when no snow was left) in 2012. Below is a sample of snowmelt observation data.

\section{Building a model for estimating the snowmelt at the snow surface}

Snowmelt (Ms: amount of snowmelt at the snow surface [Fig.1]) was calculated using the heat-balance method that has been widely used in snowmelt estimation analysis. This study first presents an outline of the heat-balance method, followed by the description of a method for calculating $M s$ from the results of observations (four types of meteorological data: temperature, precipitation, wind speed, hours of sunshine).

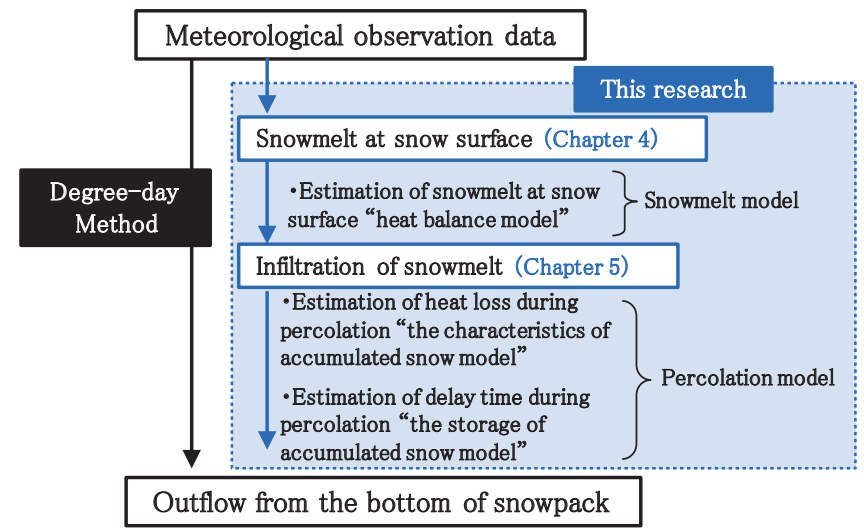

Fig. 1 Procedure for estimating outflow from under the snowpack

\subsection{Estimation of the snowmelt using the heat bal- ance method}

The heat balance method is a method for calculating the amount of heat in snowmelt estimation $\left(Q_{M}\right)$ from the heat balance at the melting snow surface (Fig.2). $Q_{M}$ at each time can be found from a heat budget equation (1).

$$
Q_{M}=Q_{R}+Q_{H}+Q_{L}+Q_{P}+Q_{C}
$$

where $Q_{R}$ is net radiation, $Q_{H}$ is detectable heat exchange, $Q_{L}$ is latent heat exchange, $Q_{P}$ is heat content of liquid precipitation, $Q_{C}$ is heat exchange at snow surface. In (1), the snow surface was defined as the reference plane, the amount of heat into the reference plane is assumed to be positive, and the amount of heat out of the reference plane negative, and the unit of heat is represented as $\mathrm{W} / \mathrm{m}^{2}$. Ms is calculated by dividing $Q_{M}\left(\mathrm{~W} / \mathrm{m}^{2}\right)$ obtained in (1) by latent heat of ice $\left(=0.334 \times 10^{6} \mathrm{~J} / \mathrm{kg}\right)$. The methods for calculating each heat quantity shown in (1) are shown below.

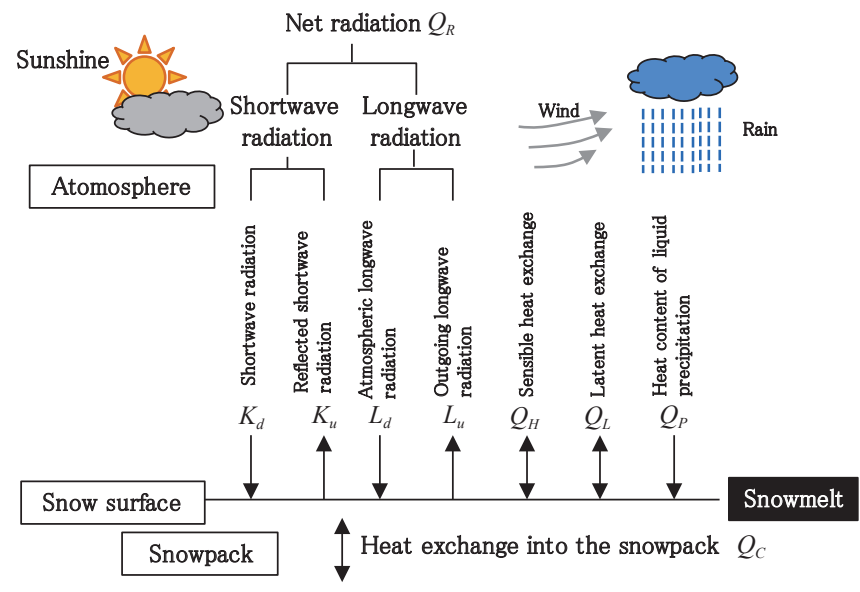

Fig. 2 Heat balance method (pictorial representation)

(1) Net radiation $Q_{R}$

Net radiation $Q_{R}$ can be found from (2) including the net shortwave radiation $K_{d}$, the reflective shortwave radiation $K_{u}$, the net longwave radiation $L_{d}$, the outgoing longwave radiation $L_{u}[3,4,5]$.

$$
Q_{R}=K_{d}+K_{u}+L_{d}+L_{u}
$$

(2) Detectable heat exchange $Q_{H}$, latent heat exchange $Q_{L}$

Detectable heat exchange $Q_{H}$ and latent heat exchange $Q_{L}$ can be found from (3) and (4) by bulk method assuming neutral atmospheric conditions.

$$
\begin{aligned}
& Q_{H}=C_{H} \rho C_{p}\left(T_{a}-T_{s}\right) u_{z} \\
& Q_{L}=C_{E} \rho l(0.622 / A P)\left(e_{z}-e_{0}\right) u_{z}
\end{aligned}
$$

where $C_{H}$ and $C_{E}$ is the bulk index for detectable heat flux and latent heat flux $\left(1.74 \times 10^{-3}\right), \rho$ is density of air $\left(\mathrm{kg} / \mathrm{m}^{3}\right)$, $C p$ is the specific heat at constant pressure $(1005 \mathrm{~J} / \mathrm{kg} / \mathrm{K})$, $\mathrm{Ta}$ is temperature $\left({ }^{\circ} \mathrm{C}\right), u z$ is wind speed at $z(\mathrm{~m})$ above the snow surface $(\mathrm{m} / \mathrm{s}), 1$ is latent heat of vaporization $(2.5 \times$ $\left.10^{6} \mathrm{~J} / \mathrm{kg}\right), A P(\mathrm{hPa})$ is air pressure at the observation site, $e_{z}(\mathrm{hPa})$ is water vapor pressure at $z(\mathrm{~m})$ above the snow surface, $e_{0}(\mathrm{hPa})$ is saturated water vapor pressure at the temperature of the surface snow.

(3) Heat content of liquid precipitation $Q_{P}$

Heat content of liquid precipitation $Q_{P}$ can be found from equation (5).

$$
Q_{P}=\rho_{w} C_{w} T_{w} P_{r}
$$

where $\rho_{w}$ is the density of water $\left(1000 \mathrm{~kg} / \mathrm{m}^{3}\right), C_{w}$ is the specific heat of water $(4.186 \mathrm{~J} / \mathrm{kg} / \mathrm{K}), T_{w}$ is wet-bulb tempera- 
ture $\left({ }^{\circ} \mathrm{C}\right), P_{r}(\mathrm{~kg})$ is precipitation.

(4) Heat exchange at the snow surface $Q_{C}$

Heat exchange at the snow surface $Q_{C}$ is generated by the temperature gradient in the snowpack. If the snow is 0 ${ }^{\circ} \mathrm{C}, Q_{C}$ is almost 0 [4]. And if there is a temperature gradient in the snow, $Q_{C}$ is smaller than the other elements. For this reason, in this study, we gave $Q_{C}$ as $0 \mathrm{~W} / \mathrm{m}^{2}$.

\subsection{Estimation of the snowmelt using four types of meteorological data}

As shown in Section 4.1, if only weather observation data have been obtained, the heat balance method could be used to calculate snowmelt at the snow surface per hour regardless of the region. However there remains a problem in that many sorts of input data are necessary for apply the conventional heat balance method to railway disaster prevention. Therefore, in this section, a method was examined to see how to incorporate the weather/outflow observation data and the result of previous studies into the estimation process of each element required for the heat balance method, and to estimate the Ms from only four weather observation data. In the following, the method for estimating each element is described.

(1) Net Radiation $Q_{R}$

The net shortwave radiation $K_{d}$ (that is given by the solar radiation onto the snow surface) was calculated from the solar radiation in the upper atmosphere [6]. The amount to be reflected at the snow surface $K_{u}$ (the reflective shortwave radiation) of $K_{d}$ reaching the snow surface could be represented by the product of reflectance (albedo) $\alpha$ and $K_{d}$. Here, it is known that $\alpha$ is variable according to the amounts of moisture and dirt of the snow surface [7], and $\alpha$ was calculated by the temperature at the time of snowfall causing, and the lapsed time after the snowfall, both of which are considered as an index. On the other hand, quantity of heat (the net longwave radiation) $L_{d}$ given to a snow surface from the clouds and water vapor of the air was presumed from $T_{a}$ and the sunshine duration $S$. Quantity of heat ejected from the snow surface towards the atmosphere (the outgoing longwave radiation) $L_{u}$ is estimated from the temperature of the snow surface $T_{s}$ [4]. In addition, $T_{s}$ was taken from the value of Table 1 which was the result of the weather/outflow observation.

Table 1 Temparature of snowsurface $T_{s}$

\begin{tabular}{|l|l|}
\hline \multicolumn{1}{|c|}{ Meteorological condition } & \multicolumn{1}{c|}{$T_{s}$} \\
\hline (a) $T_{a} \geqq 0$ & $T_{s}=0^{\circ} \mathrm{C}$ \\
\hline $\begin{array}{l}\text { (b) Night time (Solar radiation at the top } \\
\text { of atmosphere }=0 \text { ), and } T_{a} \text { is decreasing } \\
\text { (Radiative cooling arising) }\end{array}$ & $T_{s}=T_{a}-3^{\circ} \mathrm{C}$ \\
\hline Except the above (a) and (b) & $T_{s}=T_{a}^{\circ} \mathrm{C}$ \\
\hline
\end{tabular}

Table 2 Relative humidity $r h$

\begin{tabular}{|l|l|}
\multicolumn{1}{|c|}{ Meteorological condition } & $r h$ \\
\hline $\operatorname{Pr}>0$ & $r h=90 \%$ \\
\hline $\operatorname{Pr}=0$ and $T_{a}<0$ & $r h=76 \%$ \\
\hline $\operatorname{Pr}=0$ and $T_{a} \geqq 0$ & $r h=69 \%$ \\
\hline
\end{tabular}

(2) Detectable heat exchange $Q_{H}$, Latent heat exchange $Q_{L}$

The density of the air $(\rho)$ used in (3), (4) was presumed from temperature $T_{a}$, relative humidity $r h$ and local atmospheric pressure $A P[8,9,10]$. Since it is difficult to estimate $r$ from four observation data and the influence which it has on transfer heat is small, values for this parameter were taken from Table 2 based on the observational data for the past five years $(2008 \sim 2012)$ in 10 meteorological offices (Sapporo, Aomori, Akita, Morioka, Yamagata, Sendai, Niigata, Nagano, Toyama, Kanazawa) located in heavy snowfall areas. Wind velocity $\left(u_{z}\right)$ is converted from the value $\left(u_{a}\right)$ measured by an anemometer installed at height $a(\mathrm{~m})$ above the snow surface using the logarithm rule for perpendicular distribution of wind velocity [3] and setting $z$ at $2 \mathrm{~m}$ as indicated in the previous study [11]. Although snow depth $D s$ at an observation point is needed at this time, $D s$ is computable from four observation data (refer to Section 5.1). Moreover, local atmospheric pressure $A P$ was computed from temperature $T_{a}$ and the altitude of the observation point based on the sea-level atmospheric pressure reported by weather government offices [10]. Water vapor pressure $e_{x}$ was computed from $T_{a}$ and $r h$ [9]. The saturation water vapor pressure at snow surface temperature $e_{0}$ was estimated from $T_{a}$ of the observation point using the approximate Tetens expression [8].

(3) Heat content of liquid precipitation $Q_{p}$

The wet-bulb temperature used by in (5) was computed from temperature $T_{a}$, relative humidity $r h$, and atmospheric pressure of the observation point $A P$ using the expression of Sprung [10]. Moreover, as for precipitation $P_{r}$ rain/snow distribution was performed from the temperature $T_{a}$ measured when the rainfall was observed. In this research, the precipitation observed when $T_{a}$ was below $0{ }^{\circ} \mathrm{C}$ was categorized as snowfall and that observed when $T_{a}$ was over $0{ }^{\circ} \mathrm{C}$ was categorized as rain.

As mentioned above, using the method proposed this time, each of the elements shown in (1) can be determined from four observation data (temperature, precipitation, wind velocity and day light hours) which are obtained by AMeDAS etc. (Table 3).

Table 3 Estimating method of snowmelt

\begin{tabular}{|l|l|}
\multicolumn{1}{|c|}{ Quantity of heat } & \multicolumn{1}{c|}{$\begin{array}{c}\text { A meteorological } \\
\text { element required } \\
\text { for estimation }\end{array}$} \\
\hline Net Radiation $Q_{R}$ & $T_{a}, P, S$ \\
\hline Sensible heat exchange $Q_{L}$ & $T_{a}, P, u_{a}$ \\
\hline Latent heat exchange $Q_{H}$ & $T_{a}, P, u_{a}$ \\
\hline Heat content of precipitation $Q_{P}$ & $T_{a}, P$ \\
\hline Heat exchange into snowpack $Q_{C}$ & $0 \mathrm{~W} / \mathrm{m}^{2}$ \\
\hline
\end{tabular}

\subsection{Result of estimations of snowmelt}

In order to investigate the degree of difference between the quantity of heat for snowmelt $Q_{M}$ calculated from the heat balance method shown in Section 4.1 considered to be a true value and $Q_{M}$ obtained by the presumed model (refer to Section 4.2), both of the $Q_{M}$ s were computed from the observational data at Shiozawa Snow Testing Station (the 


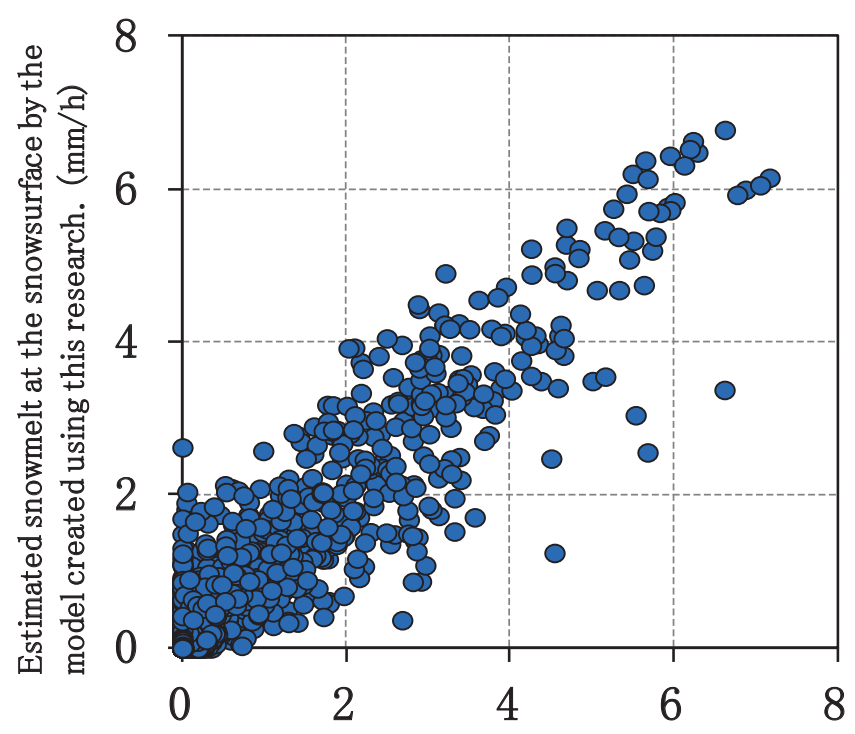

Estimated snowmelt at the snowsurface by the model created using the past research. $(\mathrm{mm} / \mathrm{h})$

Fig. 3 The result of the estimation of the outflow from under the snowpack

heat balance budget method needs seven types of observation data shown in Chapter 3 and the presumed model does four observation data shown in Section 4.2.) and were compared (Fig.3). A total of 1689 hours were available for analysis (from January 6 to April 25 in 2011) which were the data with out snow accretion to the measurement apparatus Figure 3 shows snowmelt at the snow surface $M$ (mm) converted from $Q_{M}$ using the results from the above calculation.

Although in both cases there was a maximum difference in $\mathrm{Ms}$ of $3.3 \mathrm{~mm} / \mathrm{h}$, there was such a strong correlation that the coefficient of determination was 0.87 , and the root-mean-square error (RMSE) over the true value was $0.5 \mathrm{~mm} / \mathrm{h}$. Moreover, comparing the integrated value of $M$ during the observation, the true value was $1202 \mathrm{~mm}$ and the value acquired from the presumed model was $1266 \mathrm{~mm}$, and this result shows both were in agreement in general. As mentioned above, it turned out that the presumed model created by this research can estimate $M$ without the use of the heat balance method which needs many observation data.

\section{Development of a model for estimating snowmelt infiltration}

In order to reproduce the phenomenon of snowmelt infiltration, it is necessary to consider the influences of heat loss (refer to Section 5.1.) and time delay (refer to Section 5.2.). This chapter describes the snowmelt infiltration model created on the basis of weather/outflow observations and the results of previous studies.

\subsection{Development of a model for estimating the char- acteristics of accumulated snow}

Even if snow melt at the snow surface, when there is a snow layer below $0{ }^{\circ} \mathrm{C}$ in the snowpack, a part or all of the quantity of heat is used for rising the temperature of the snow pack, and melting water could not reach the bottom of snowpack (Fig.4). As a result snowmelt at the snow surface $M_{s}$ and outflow from the bottom of snowpack $M_{b}$ are not necessarily in agreement. Consequently, in order to estimate $M_{b}$ with sufficient accuracy, it is necessary to compute the loss of heat for fusion (called heat loss). In addition, in case all layers of snowpack are $0{ }^{\circ} \mathrm{C}$, the quantity of heat loss is $0 \mathrm{~W} / \mathrm{m}^{2}$.

In this research, in order to compute heat loss temperature, "the snow coverage quality model" which estimates physical-property values of a snow layer (one layer of snow is formed in 1 hour) such as temperature of each snow layer, snow depth, density, weight etc. from four observation data. This model can estimate snow temperature $T_{s}$ in consideration of heat loss, and outflow from snowpack $M_{b}$ by adding $Q_{M}$ to the input value of the past viscous compression model $[12,13]$. The calculation method of $T_{s}$ and $M_{b}$ examined in this research is as follows. First, we calculate snow temperature of each layer from the surface to the bottom using temperature $T_{a}$ [13]. Next, in order to compute heat loss, the quantity of heat required for raising the temperature of each layer to $0{ }^{\circ} \mathrm{C}$ is calculated from (6).

$$
Q_{A}=C_{i} w T_{S} / 3.6
$$

where $C_{i}$ is the specific heat of ice $\left(2.1 \times 10^{3} \mathrm{~J} /{ }^{\circ} \mathrm{C} / \mathrm{kg}\right)$, and $\mathrm{w}$ is the mass of each snow layer $\left(\mathrm{kg} / \mathrm{m}^{2}\right)$. The difference in heat loss of each snow layer $Q_{A}$ was calculated by the heat of fusion $Q_{M}$ which the infiltrating snowmelt contained from the surface to the bottom of the snowpack Then, the heat loss of each snow layer was calculated in consideration of the heat of fusion (Fig. 4). The heat of fusion in consideration of heat loss $Q_{M}$ ' was obtained by deducting the amount of heat of fusion $Q_{M}$ from the integrated value of the heat loss of each snow layer $\Sigma Q_{A}$ computed by this series of calculations. In this model, even if snow melted at the snow surface when $Q_{M}$ was smaller than $\Sigma Q_{A}, M_{b}$ was

(1) Case of no outflow from the bottom of snowpack

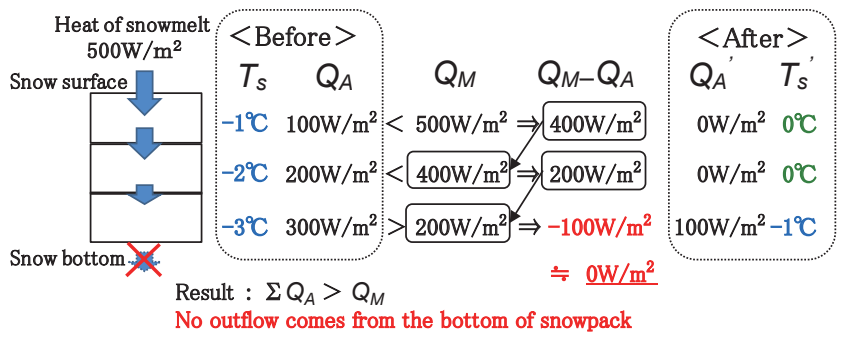

(2) Case of outflow from the bottom of snowpack

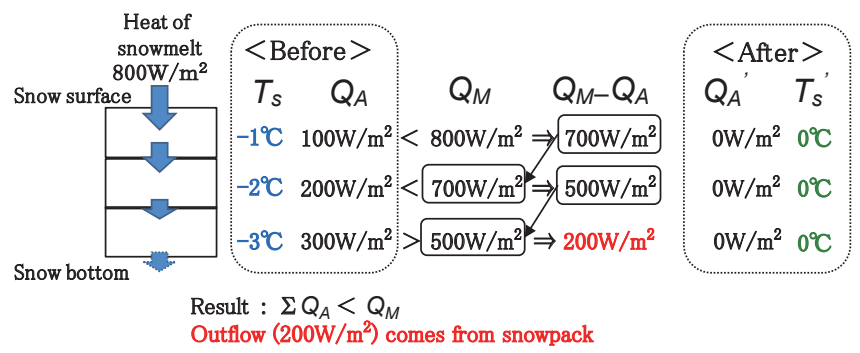

Fig. 4 Method for estimating snow temperature and outflow 
computed at $0 \mathrm{~mm}$ since the heat of fusion is used to obtain the rise in $T_{s}$. In this research, $M_{b}$ was continuously estimated by repeating the abovementioned calculation every hour over a whole winter. In addition, in this calculation process, $T_{s}^{\prime}$ in consideration of heat loss can be found by substituting $Q_{A}$ for (6).

\subsection{Development of a model for estimating accumu- lated snow}

When rain and snowmelt infiltrate thorough snowpack, we must consider the influence of the storage effect i.e., the problem of "delay time" process. Delay time is the time lag between snow melting on the snow surface until it reach the bottom of the snowpack. This influence cannot be disregarded in the estimation of the outflow from the bottom of snowpack in units of hours. In a recent study [14] [15], assuming the infiltration of snowmelt through saturated snow layer, the outflow from the snowpack $M(t)$ is estimated with the delay time (t) according to the Darcy's law (7). The research in question also used this technique.

$$
\begin{aligned}
& M_{b}^{\prime}(t)=M_{b}^{\prime}(t-1) \exp \left(-1 / k_{0}\right)+M_{b}(t)+P_{r}(t) \\
& -\left\{M_{b}(t)+P_{r}(t)\right\} \exp \left(-1 / k_{0}\right)+M_{g}(t)
\end{aligned}
$$

Where $M_{b}^{\prime}(t-1)$ is the outflow from the snowpack 1 hour before the time (t) (delay time is taken into consideration), $k_{0}$ is the coefficient of storage which expresses the delay time, $M_{b}(t)$ and $P_{r}(t)$ are outflow and precipitation in time $t$ (without considering delay time), respectively. $M_{b}$ is the amount of snowmelt at the bottom of the snowpack (snowmelt generated by ground warmth), referred to as 0.075 $\mathrm{mm} / \mathrm{h}$ [16] throughout this research. It is known that delay time is dependent on snow depth or the structure of the snow layer. And in this research, $k_{0}$ was given as a function of snow depth $D_{s}$ from the result of the weather/outflow observation in the Shiozawa Snow Testing Station. In addition, at the present stage, it is difficult to presume the structure of snow layer with sufficient accuracy, and there are many unknown variables in the relationship between the structure of the snow layer and the delay time. For this reason, the influence of snow layer structure on delay time was denoted by functions of $k_{0}$ and $D_{s}$. When obtaining the functions of $k_{0}$ and $D_{s}$, it is considered that 24 hours are one snow melting event. And the period of the event is ten days during which the estimated outflow of 24 hours $\Sigma M_{b}(t)$ and the observed outflow of 24 hours $\Sigma M_{b}(t)$ are mostly in agreement and daily variation is clear. Next, $M_{b}^{\prime}(t-1)$ and $M_{b}(t)$ which are the input values for each time were substituted in (7) to obtain $M_{b}^{\prime}(t)$.

After this, $k_{0}$ was sought for every snowmelt event by trial and error until the smallest integrated value of the square error of the calculated $M_{b}^{\prime}(t)$ and the measured $M_{b}^{\prime}(t)$, obtained from a lysimeter, was found. The relation of $k_{0}$ and $D_{s}$ calculated by the above method is shown in Fig. 5. In this Figure, it can be observed that the longer the penetration time is, the larger $k_{0}$ is, and that when $D_{s}$ exceeds $1.5 \mathrm{~m}$, $k_{0}$ becomes remarkably large. Therefore, in this research, it was presupposed that the relation of $k_{0}$ and $D_{s}$ is expressed with an exponential function as shown in the (8) and (9) [14].

$$
D_{S}>0.5(\mathrm{~m}), \quad k_{0}=1.654 \exp \left(1.143 D_{S}\right)
$$

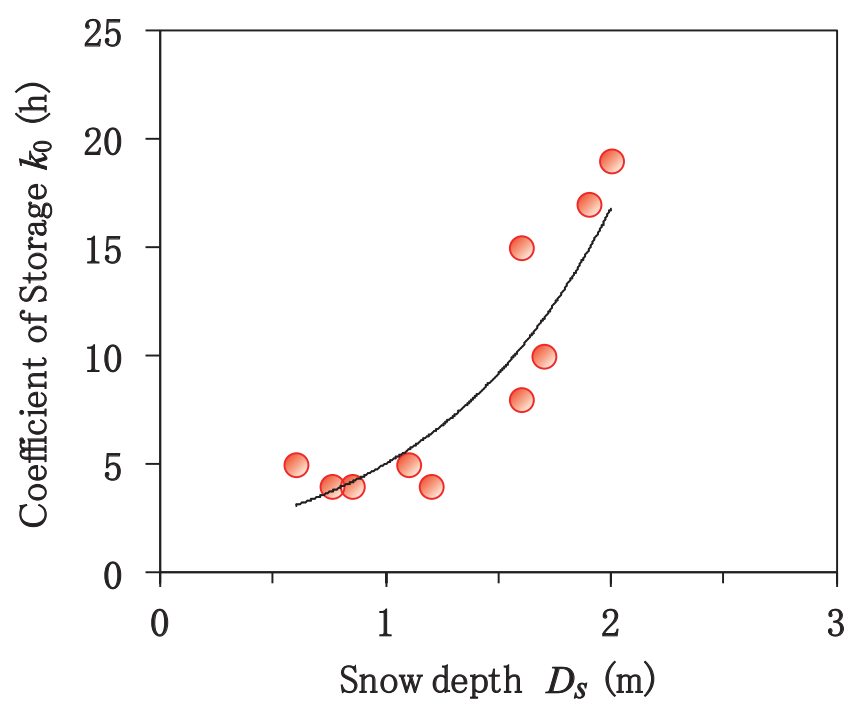

Fig. 5 The relationship of $k_{0}-D_{s}$ observed at the Shiozawa Snow Testing Station

$$
0.5 \geqq D_{S}>0(\mathrm{~m}), \quad k_{0}=1.654
$$

In addition, since $k_{0}$ may be subject to not only $D_{s}$ but the snow layer structure etc., it is also assumed that $k_{0}$ is changing depending on the area or years. Therefore, continuous examination about how to give $k_{0}$ and the applicable condition of (8) is required.

\section{Result of estimation of the outflow from under ac- cumulated snow}

According to the estimation procedure shown in Fig.1, The outflow $M_{b}^{\prime}$ computed from a series of models shown in Chapter 4 and Chapter 5 was compared with actual measurements of $M_{b}^{\prime}$ obtained from observation data from the Shiozawa Snow Testing Station. As a result, the estimated peak value of $M_{b}$ and the appearance time of the peak showed the proximity to the observed value actually (Fig.6). Figure. 7 shows the result of the comparison between the estimated values and the observed values during the whole observation period. Although at peak level, both values have a difference of $4.3 \mathrm{~mm} / \mathrm{h}$, the root-mean-square errors (RMSE) over the actual measurement are $0.5 \mathrm{~mm} / \mathrm{h}$, and both values correlate well. Estimating $M_{b}$ with not only the estimated model of snowmelt at the snow surface but also the infiltration model of the snowmelt have been created

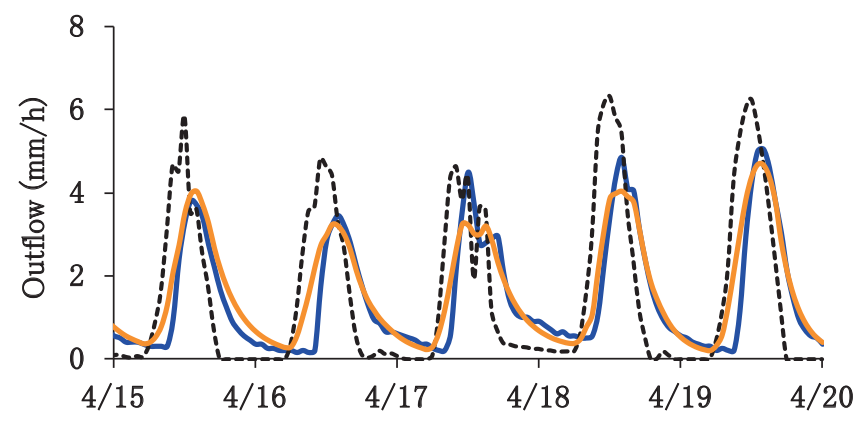

Fig. 6 Outflow from under the snowpack 


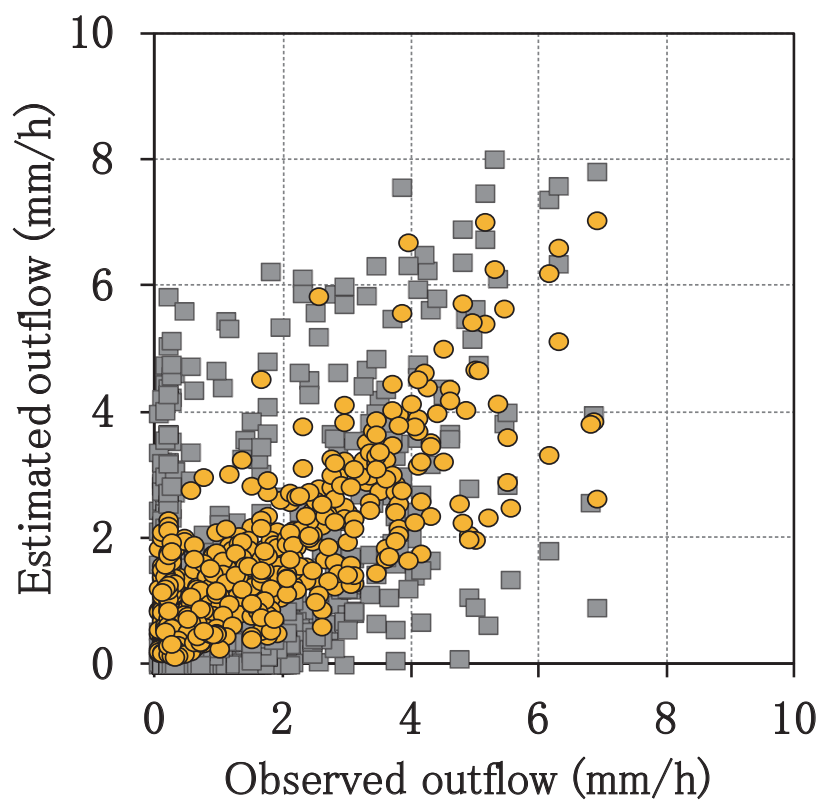

Fig. 7 The estimated outflow from under the snowpack

in this research, the RMSE of $M_{b}$ (estimated value) was decreased by about $45 \%$, compared with the presumed model which infiltration process is not taken into consideration.

The estimation method proposed in this paper makes it possible to estimate the outflow from the bottom of the snowpack per hour from only four types of observation data (temperature precipitation, wind velocity, and daylight) collected from AMeDAS observation points etc. which can be obtained easily, and the time resolution of the estimate is better compared to the past degree day method. In addition, by including the snow coverage quality model in the estimation process, the influence of snow temperature could be taken into consideration and the rain and thaw phenomenon accompanied by a temporary temperature rise in the middle of winter could also be evaluated. However since many underestimated or overestimated points are observed in the actual measurement as shown in Fig.7, the continuous examination of the estimation of snow temperature or the method of setting the coefficient of storage is required.

\section{Conclusion}

This research examined a method for estimating outflow from under a snowpack which is closely related to the generation of a full depth avalanche. The method proposed in this paper makes it possible to estimate the outflow from under the snowpack per hour from four types of observation data (temperature, precipitation, wind velocity, daylight) collected from nearby AMeDAS points. For this reason, its application to railroad disaster prevention (for example, a point where the observation of the outflow from the snowpack is difficult because of problems such as inaccessibility due to surrounding environment) is expected.

From now on, while aiming at the improvement and extension of the estimated method, we advances analysis about the relation between the outflow and the stability of the snowpack that is the danger index of a full depth avalanche. And we would like to establish a stability assessment method of snowpack on the slope. In addition, further research aims to explore the application of these methods to earth-and-sand collapse, etc.

\section{References}

[1] Kawashima, K., Iikura, S., Sugiyama, T., Endo, T., Fujii, T.: "Development of a simple method foe estimating daily amount of snowmelt with the object of application to railway disaster prevention," Seppyo, Vol.64, No.6, pp.605-615, 2002 (in Japanese).

[2] The Japanese Society of Snow and Ice Hokkaidobranch : "Snow Survey Method," Hokkaido University Press, pp.137-152, 1991 (in Japanese).

[3] Kondo, J.: "Atmospheric Science near the Ground Surface," University of Tokyo Press, pp.82-165, 2000 (in Japanese).

[4] Maeno, K., Fukuda, M.: Snow Ice Water Phenomenon, Basic Lecture of Glaciology VI, Kokon-Shoin, pp.1792, 1994 (in Japanese).

[5] J. E. Hay, B.B. Fitzharris : "A comparison of the energy-balance and bulk-aerodynamics approaches for estimating glacier melt, " Journal of Glaciology, Vol.34, No. 17, 1988.

[6] Kun, Y., Toshio, K.: "A general model to estimate hourly and daily solar radiation for hydrological studies," Water Resources Research, Vol.41, 2005.

[7] Yamazaki, T., Taguchi, F., Kondo, J.: "Estimation of the heat balance in a small snow-covered forested catchment basin," Tenki, Vol.41, No.2, pp.3-9, 1994 (in Japanese).

[8] Kondo, J.: Meteorology of water environment - Water and Heat Budget -at the Ground Surface -, Asakura Publishing Co., Ltd., 1994 (in Japanese).

[9] Meteorological Society of Japan : "Weather observation -The volume on meteorological observation at the ground," Meteorological research note, Vol.185, pp.112, 1996 (in Japanese).

[10]Japan Meteorological Agency : "Indicator of Meteorological Observation at the Ground, "Japan Meteorological Business Support Center, 2002 (in Japanese).

[11] Pellicciotti, F., Helbing, J., Rivera, A., Favier, V., Corripio, J., Araos, J., Sicart, J., Carenzo, M.: “A study of the energy balance and melt regime on Juncal Norte Glacier, semi-arid Andes of central Chile, using melt models of different complexity, "Hydrological Processes, Vol.22, pp.3980-3997, 2008.

[12]Endo, Y., Kominami, Y., Yamanoi, K., Takeuchi, Y., Murakami, S., Niwano, S.: "Calculation method of snow depth and density from precipitation data," Seppyo, Vol.66, No.1, pp.17-25, 2004 (in Japanese).

[13] Suizu, S.: “A hazarded evaluation model of dry snow avalanches caused by heavy snowfall, "Seppyo, Vol.64, No.1, pp.15-24, 2002 (in Japanese).

[14]Nakatsugawa, M., Kudo, K., Hoshi, K.: "Generalized Analysis of Runoff Due to Snowmelt Considering Storage of Accumulated Snow, " Papers of Hydraulic Engineering, Vol.48, pp.37-42, 2004 (in Japanese).

[15]Matsumoto,T., Kawashima,K., Togari,A., Shimamura, 
M.: "Estimation of outflow from the bottom of a snowpack using a combination of a temperature-radiation index snowmelt model and a percolation model, "Seppyo, Vol.72, No.4, pp.255-270, 2010 (in Japanese).
[16]Izumi, K.: "Amount of snowmelt from the bottom of snowpack," Ann. Rep. Saigai-ken Niigata Univ., Vol.5, pp.123-125, 1983 (in Japanese).

\section{Authors}

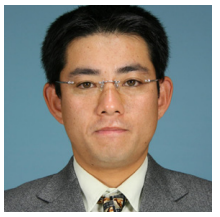

Masaya SHISHIDO

Assistant Senior Researcher, Meteorological Disaster Prevention Group Disaster Prevention Technology Division

Research Areas: Snow and Ice Related Disaster Countermeasures of Railroad

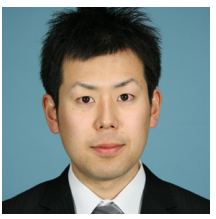

Yasushi KURIHARA

Researcher, Meteorological Disaster Prevention Group (Former)

Disaster Prevention Technology Division

Research Areas: Snow and Ice Related

Disaster Countermeasures of Railroad

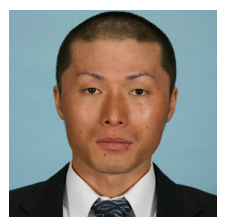

Daisuke TAKAHASHI

Researcher, Meteorological Disaster Prevention Group

Disaster Prevention Technology Division

Research Areas: Snow and Ice Related

Disaster Countermeasures of Railroad

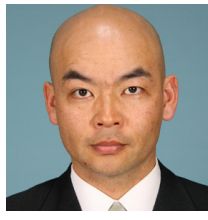

Yasushi KAMATA, Ph.D.

Senior Researcher, Meteorological Disaster Prevention Group

Disaster Prevention Technology Division

Research Areas: Snow and Ice Related

Disaster Countermeasures of Railroad

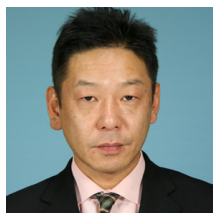

Shigehiro IIKURA, Ph.D.

Laboratory Head, Meteorological Disaster Prevention Group

Disaster Prevention Technology Division

Research Areas: Snow and Ice Related

Disaster Countermeasures of Railroad 